\title{
Influence of Preformed Adherent Angle and Reinforcing Glass Fibre on tensile strength of Hybrid Adhesive Bond
}

\author{
Viktor Koláŕr ${ }^{1}$, Miroslav Müller ${ }^{1}$, Martin Tichý ${ }^{1}$, Anna Rudawska², Monika Hromasová ${ }^{1}$ \\ ${ }^{1}$ Faculty of Engineering, Czech University of Life Sciences Prague, Kamýcká 129, 16500 Praha 6 -Suchdol, Czech \\ Republic. E-mail: vkolar@tf.czu.cz, muller@tf.czu.cz, martintichy@tf.czu.cz, hromasova@tf.czu.cz \\ ${ }^{2}$ Politechnika Lubelska, Faculty of Mechanical Engineering, Lublin, Poland. E-mail: a.rudawska@pollub.pl
}

\begin{abstract}
Adhesive bonding technology present a perspective method of various materials bonding and replacing conventional bonding e.g. welding. A geometric shape modification of bonding material and an adhesive reinforcing by glass fibres to increase tensile strength of adhesive bond was subject of this research. The bonding material was modified into preformed angles $5^{\circ}, 10^{\circ}, 15^{\circ}, 20^{\circ}$ and adhesive bond with $0^{\circ}$ was set as the etalon. The adhesive was modified by glass fibre with weight 80,110 and $160 \mathrm{~g} \cdot \mathrm{m}^{-2}$. The research proved tensile strength increase from 4 to $\mathbf{4 8 \%}$ by various preformed adherent angles. The research also proved tensile strength increase from 4,8 to $93,7 \%$ by adhesive reinforcing with glass fibres with various weight. Statistical analyse proved significant difference between measured values on significance level 0.05 ( $p<0.05)$ i.e. influence of adhesive bond modification on mechanical properties was proved.
\end{abstract}

Keywords: Mechanical properties, glass fabric, reinforcing adhesive layer, SEM, preformed angle

\section{Introduction}

Adhesive bonding technology replace a conventional material bonding in practical application in world industry [1], [2]. This technology provides various advantages against conventional technologies which includes:

- lower construction weight,

- better damage resistance,

- flexibility of entire construction element [3], [4].

Single side overlap adhesive bond is most used adhesive bond in current industry for its simply assembly and low manufactory cost. The tensile stress is converted through an adhesive layer from one side to other side of bond. This problematic is researched by several authors from all world [5]-[10]. A constructional shape of adhesive bond deals with a mutual position of bonded parts in such way to gain a given contact area. The constructional shape of the adhesive bond finds a practical application at connecting of plain areas that means sheets of metal above all [11].

However, there is several researches into improving the adhesive bond strength. Increase of the adhesive bond strength is possible by special constructional adjustments, by a choice of a material, by an increase of a length and a width of the overlapping [11].

A overlap length change is on of possibilities. The problem is that overlap does not increase bond strength from certain length. This fact is given by stress concentration at peaks on the begin to the end of bond where the highest force is there. The middle part is stressed by substantially lower force [12]. An interesting modification method is a notch in adherent to increase adhesive bond strength [13]. Other authors dealt with adherent modification into wavy shape in their researches and proved strength increase of an adhesive bond [11], [15]-[18]. Increase of adhesive bond strength ranged in interval from 27 to $560 \%$ by galvanized adherent [11]. A peeling at the shear-tensile stress in edges of the adhesive layer was decreased [11], [15]-[17].

Next possibility is a geometric shape modification of overlap bond. Author You at al. [15] calculated an optimal preformed angle of adherent based on adherent thickness, adhesive layer thickness and loading force $F$ [9], [19]. The optimal angle is $9.98^{\circ}$ for overlap length 12.5 $\mathrm{mm}$ and adherent thickness $2 \mathrm{~mm}$ according to the calculation. The preformed angle optimalization is calculated from formula (1). An adhesive bond increase was proved by this modification [18].

$$
\beta=\arctan \left(\frac{t+n}{l}\right)
$$

Where:

$\beta$ - preformed angle $\left(^{\circ}\right)$,

$\mathrm{t}$ - adherent thickness (mm),

$\mathrm{n}$ - adhesive layer thickness (mm),

1 - overlap length ( $\mathrm{mm})$.

Different deformation occurs by adhesive bonds with uneven adhesive layer. An uneven adhesive layer occurs at single lap bonds. The deformation is more progressive in the edges of overlap bond where stress peaks arise [19], [20]. The stress concentration on overlap bond edges is increased by bending moment which initiates adhesive bond fraction. The reason is uneven stress distribution in adhesive layer caused by flexibility and deformation of adherend [19], [20]. This negative status caused the initiation of cracks and their subsequent distribution which leads to adhesive bond destruction. [11], [19], [20]. This caused decrease of adhesive bond strength [9], [19].

A reinforcing layer in fabric form is significant benefit for adhesive bonds. Researches about fabric based on synthetic and biologic fibres show positive influence on adhesive bond strength increase [9], [21], [22]. Use of a reinforcing fabric in adhesive layer leads to increase of adhesive layer uniformity [11], [22]. 
Geometric shape modification and reinforcing of adhesive layer by glass fabric to increase adhesive strength is the primary aim of the research. The secondary aim is single lap bonds application improvement in practice.

\section{Material and methods}

Adhesive bonds were manufactured by two parts epoxy resin CHS-Epoxy 324 (Epoxy 1200). Polyamide hardener CHS P11 was use for cure the epoxy resin in ratio 100 (epoxy) : 7 (hardener) according to technical list. Impregnated glass fabric (E-sklo) treated by a wax was used for adhesive modification with weight 80,110 (Fig. $1 \mathrm{~A}$ ) and $160 \mathrm{~g} . \mathrm{m}^{-2}$ as reinforcing phase. A structure of adhesive bond reinforced by glass fabric is evident from Fig. 1 B. Figure 1 B shows disposition of glass fabric in adhesive layer i.e. weft and warp. The warp is a carrier element of the fabric. The weft bonds fibres together. From Fig. $1 \mathrm{C}$ is evident a circular cross-section of glass fibre warp. From Fig. $1 \mathrm{~B}$ and $\mathrm{C}$ is evident good wettability of reinforcing phase in adhesive which is a primary assumption for quality adhesive bond.

Parameters of warp and weft at used fabrics were following: 80 g.m $\mathrm{m}^{-2} 12 \times 12 \mathrm{~cm}, 110$ g.m $\mathrm{m}^{-2} 16 \times 15 \mathrm{~cm}, 160$ g. $\mathrm{m}^{-2} 12 \times 12 \mathrm{~cm}$. An adherent for adhesive bond was sheet of aluminium alloy EN AW $2024 \mathrm{~T} 3\left(\mathrm{AlCu}_{4} \mathrm{Mg}_{1}\right)$ with thickness $1.6 \mathrm{~mm}$ and size of semi-product $1000 \mathrm{x}$ $2000 \mathrm{~mm}$.

Adherents were preformed into angle $\alpha$ (Fig. 2) with size $0^{\circ}$ (no modification), $5^{\circ}, 10^{\circ}, 15^{\circ}$ and $20^{\circ}$. Adherents were surface treated before adhesive layer application i.e. mechanical blasting by abrasive GARNET MESH 80 in blasting chamber and chemically cleaned in acetone bath. This preparation process of adhesive surface was optimal proved [23].

Then was adhesive layer applied on both part of adherents to improve wettability of reinforcing layer from glass fabric. Standard ČSN EN 1465 establish overlap length on $12.5 \mathrm{~mm}$. The overlap length was extended on $25 \pm 0.41 \mathrm{~mm}$ (Fig. 1) for easily application of fabric and more significant results. The adhesive bonds were loaded by $750 \mathrm{~g}$ and left to cure of adhesive for 48 hours with temperature $21 \pm 1{ }^{\circ} \mathrm{C}$ and relative humidity $53 \pm 3 \%$. Testing series contained 7 samples. Characteristic and designation of adhesive bonds is evident from Tab. 1. A cross section of adhesive bond with reinforcing fabric is evident from Fig. 1 B, C.

Universal testing machine LABTest 5.50ST with measuring unit AST KAF $50 \mathrm{kN}$ and evaluation software Test\&Motion was used for establishing the strength of adhesive bond according to ČSN EN 1465. Loading speed was set on $2 \mathrm{~mm} . \mathrm{min}^{-1}$ to keep time standard ( $65 \pm$ $25 \mathrm{~s}$ ) for the adhesive bond tensile test. Type of bonding failure is described according to ISO 10365. An electron microscopy (SEM) was used for better understanding of mechanical properties by MIRA 3 TESCAN GMX. The testing samples were dusted by gold with device Quorum Q150R ES.
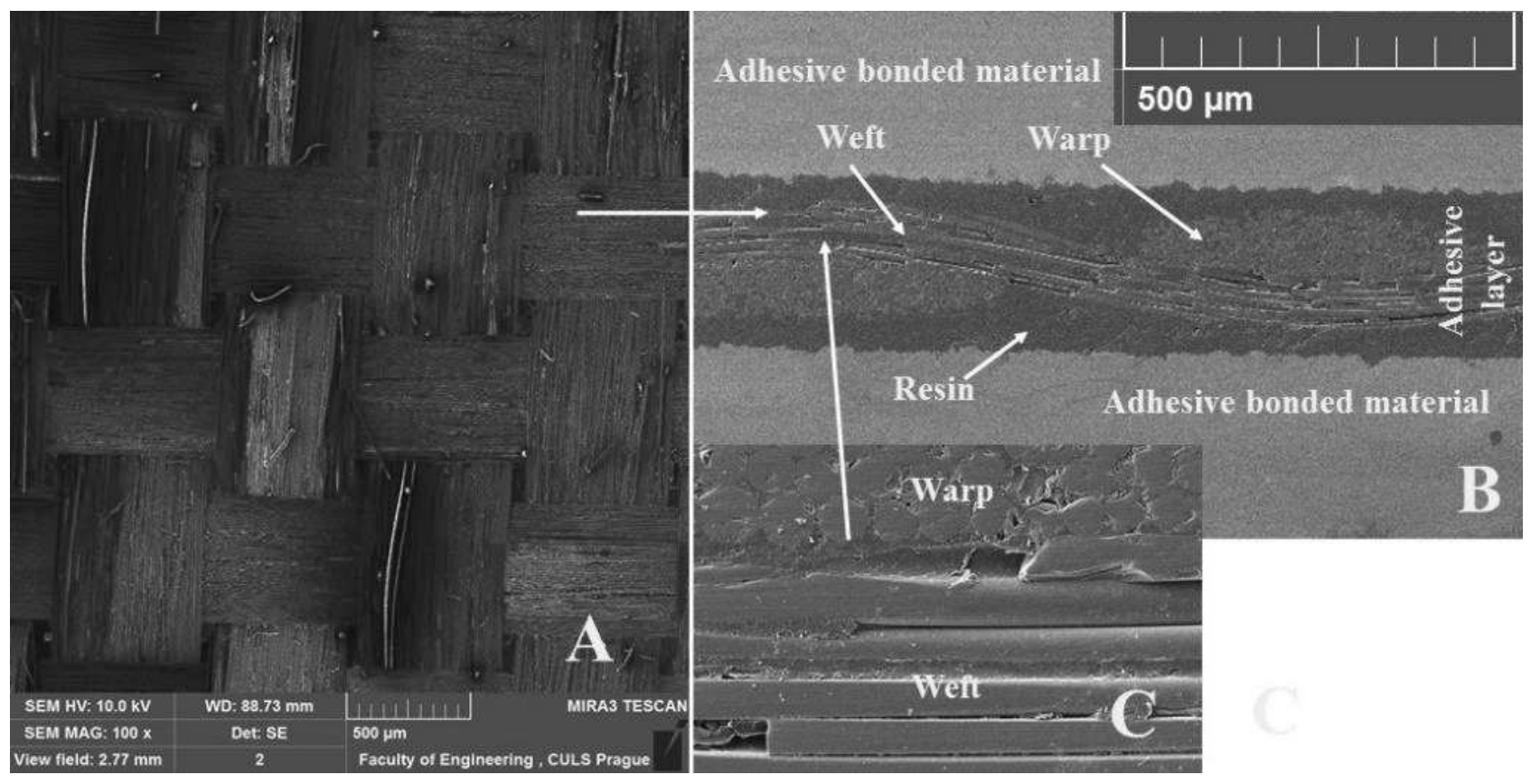

Fig. 1 Testing sample: A: SEM images of reinforcing phase-glass fabric 110 g.m $\mathrm{m}^{-2}$, (MAG $100 x$ ): B: Cross-section of adhesive bond with reinforcing phase in form glass fabric, $C$ : detailed view on reinforcing phase and its dispositionWarp and Weft.

Tab. 1 Basic characteristics of tested adhesive bonds

\begin{tabular}{|c|c|}
\hline Adhesive bond characteristics & Designation \\
\hline Resin & R \\
\hline Resin - reinforcement in form of E glass fabrics 80 g.m $\mathrm{m}^{-2}$ & RRG80 \\
\hline Resin - reinforcement in form of E glass fabrics $110 \mathrm{~g} \cdot \mathrm{m}^{-2}$ & PRGF160 \\
\hline Resin - reinforcement in form of E glass fabrics $160 \mathrm{~g} \cdot \mathrm{m}^{-2}$ & \\
\hline
\end{tabular}



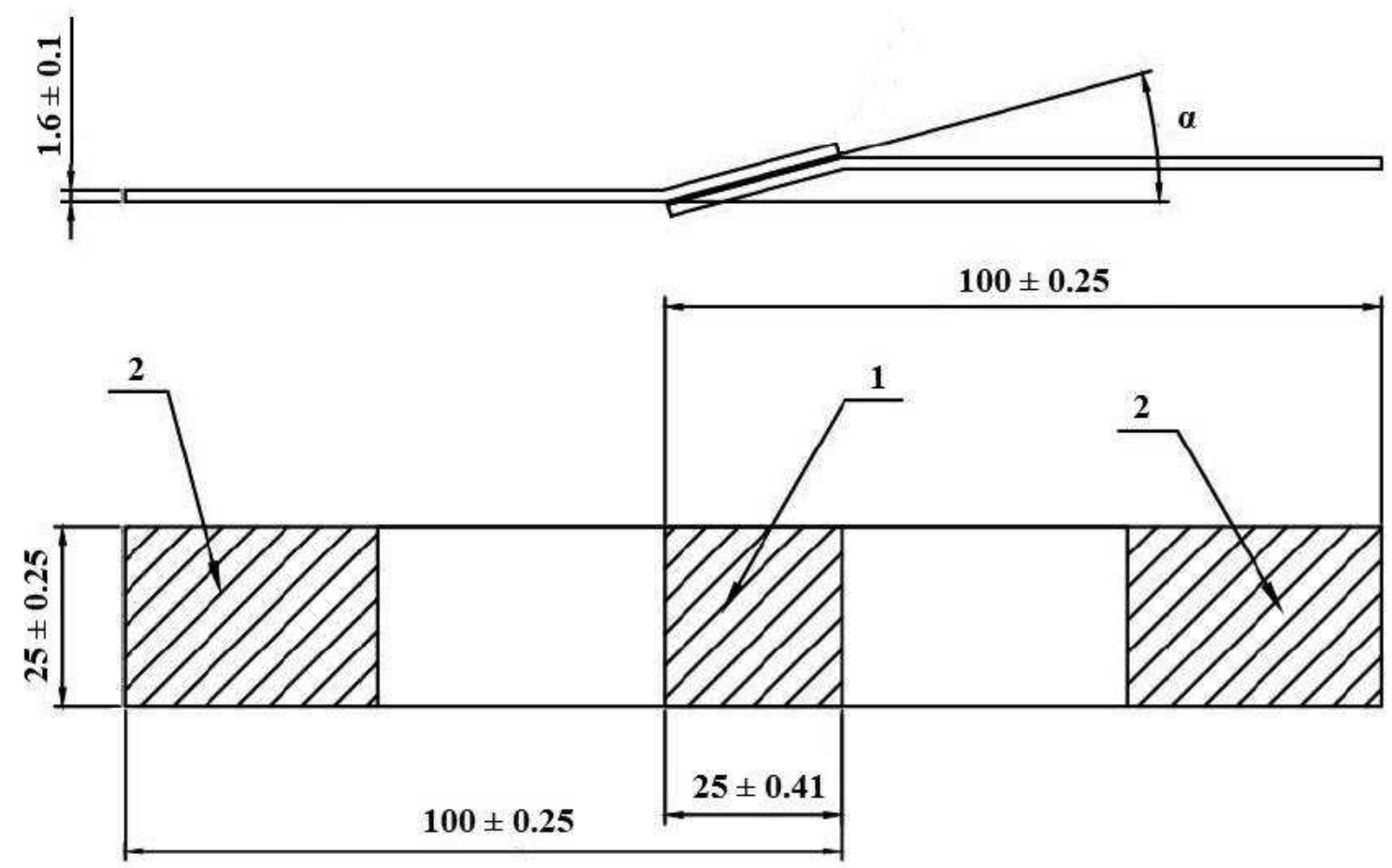

Fig. 2 Adhesive bond-1. overlap bond, 2. clamping surface in testing machine jaws, $\square \square$-preformed angle of adherent.

Anova F-test was used to evaluation of measured values by program STATISTICA. An F-test is any statistical test in which the test statistic has an $\mathrm{F}$ distribution under the null hypothesis $\left(\mathrm{H}_{0}\right)$. It is most often used when comparing statistical models that have been fitted to a measured data set, in order to identify the model that best fits the population from which the measured data were sampled. A difference between values was evaluated by $p$ parameter. A significant level was established on 0.05 . Hypothesis $\mathrm{H}_{0}$ marks statistically nonsignificant difference between measured values i.e. $p>0.05$. Hypothesis $\mathrm{H}_{1}$ rejects hypothesis $\mathrm{H}_{0}$ and marks statistically significant difference i.e. $p<0.05$.

\section{Results and discussion}

The strength of no modification adhesive bond " $R$ " $8.82 \pm 0.54 \mathrm{MPa}$ is shown on fig 3 . The highest adhesive bond strength $13.1 \pm 0.25 \mathrm{MPa}$ was achieved when using fabric $80 \mathrm{~g} \cdot \mathrm{m}^{-2}$ and adherent modified angle $5^{\circ}$. The strength was therefore increased up to $23.2 \%$ compared to angle $0^{\circ}$ with the identical fabric. Strength increase was achieved up to $48.45 \%$ in comparation with no modification adhesive bonds. The highest average strength $12.54 \pm 0.50 \mathrm{MPa}$ was achieved with angle $5^{\circ}$ regardless of fabric application which is increase up to $17.86 \%$ against angle $0^{\circ}$. The lowest adhesive bond strength 9.55 $\pm 2.59 \mathrm{MPa}$ was achieved with adherent angle $20^{\circ}$ (Fig. 3 ). The strength of adherent modified angle $20^{\circ}$ decrease up to $28.69 \%$ on $6.29 \pm 1.51 \mathrm{MPa}$ against the adherent with no modification.

Author You et al. [18] modified adherents into various preformed angles in his research and achieved the strength increase up to $64 \%$ with modified angle $7^{\circ}$.
Modified angle $10^{\circ}$ increased the strength up to $34 \%$ which respond to results of this research for no fabric modification adhesive bonds [18]. The optimal preformed angle $\beta$ was calculated with measured values by formula (1) for adhesive bonds mark R and RRGF in interval from $3^{\circ} 40^{\prime}$ (adhesive bonds $-\mathrm{R}$ ) to $3^{\circ} 59^{\prime}$ (adhesive bonds RRGF160). The adhesive thickness was changed in interval from 0.1 to $0.24 \mathrm{~mm}$ for adhesive bonds.

An influence of preformed adherent angle is inhomogeneous group in view of statistical testing i.e. there is a statistically significant difference between measured values. The values of parameter $p$ are lower than established significance level 0.05 (Tab. 2). It is proven that preformed adherent angle significantly influence the strength and elongation at break of the adhesive bond.

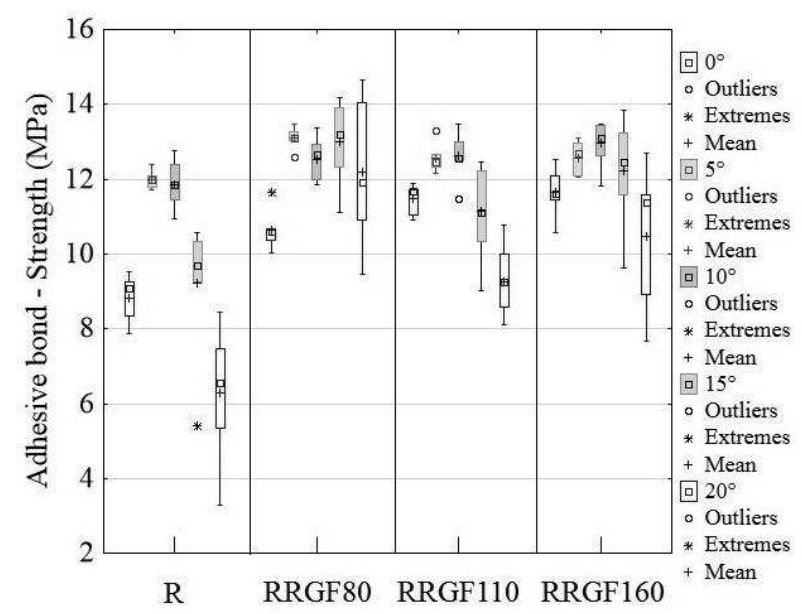

Fig. 3 The influence of preformed adherent angle and reinforcing glass fabric on adhesive bond strength 
Tab. 2 The statistical testing values of $p$ paramter on influence of preformed angle on adhesive bond strength

\begin{tabular}{|c|c|c|}
\hline $\begin{array}{c}\text { Preformed } \\
\text { adherent angle }\left({ }^{\circ}\right)\end{array}$ & $\begin{array}{c}p \text { parametr } \\
\text { (strength) }\end{array}$ & $\begin{array}{c}p \text { parametr } \\
\text { (elongation at } \\
\text { break) }\end{array}$ \\
\hline 0 & 0.0000 & 0.0000 \\
\hline 5 & 0.0002 & 0.0013 \\
\hline 10 & 0.0144 & 0.0007 \\
\hline 15 & 0.0002 & 0.0001 \\
\hline 20 & 0.0000 & 0.0002 \\
\hline
\end{tabular}

Weight of used reinforcing glass fabric is inhomogeneous group in view of statistically testing i.e. there is a statistically significant difference between measured values. The values of parameter $p$ are lower than established significance level 0.05 (Tab. 3). It is proven that weight of fabric significantly influence adhesive bond strength.

Tab. 3 The statistical testing values of p paramter on influence of reinforcing fabric weight on adhesive bond strength

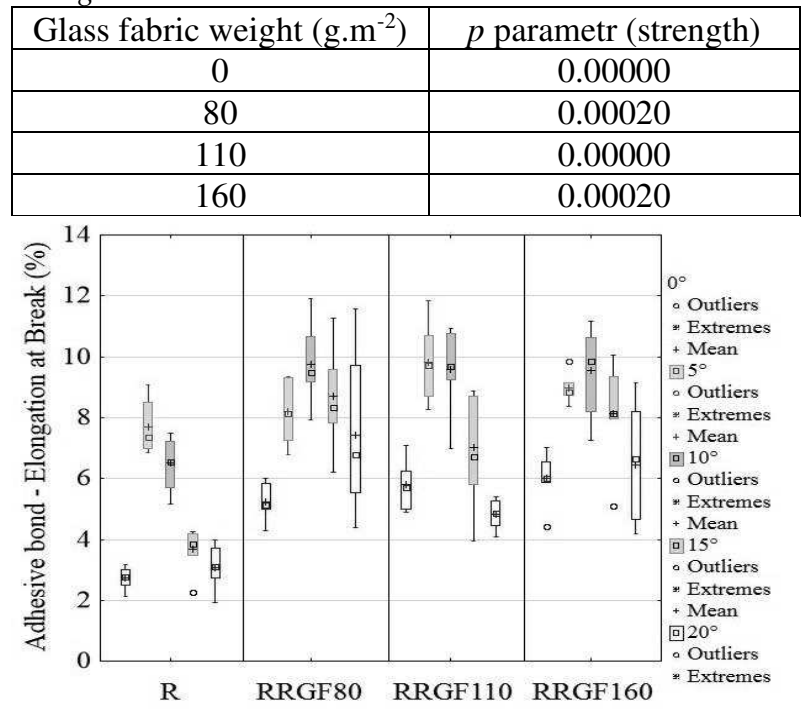

Fig. 4 The influence of preformed adherent angle and reinforcing glass fabric on elngation at break od adhesive bond
The results of elongation at break of adhesive bonds with various preformed adherent angles and used reinforcing glass fabric presents Fig. 4. The results show an increase of elongation at break influenced by preformed adherent angle and used reinforcing fabric.

SEM images (Fig. 5) shows fracture surface of adhesive bonds. The adhesive bond $\mathrm{R}$ (no reinforcing fabric) showed significant representation of adhesive failure i.e. adhesive layer delamination from adherent (Fig. 5 A). On Fig. $5 \mathrm{~A}$ are evident tracks and abrasive particles on adherent after mechanical surface treatment. This microparticles Garnet MESH 80 penetrated into adherent surface and was not removed even chemically cleaning in Acetone bath. Fig. $5 \mathrm{~B}$ and $\mathrm{C}$ presents fracture surface of adhesive bonds RRGF160 reinforced by glass fabric. The glass fabric in adhesive layer increased adhesive bonds strength in interval from 4.8 to $93.7 \%$ (related to adhesive bond $\mathrm{R}$ with no reinforcing) and changed facture surface. The fracture surface was adhesively cohesion with prevailing cohesion fracture i.e. a failure inside of adhesive layer. The fracture surface change was caused also by preformed angle. The same results achieve You at al. [15] and Santana et al. [24]. A significant increase of adhesive bond strength reported all three testing fabric where the weight 80 g. $\mathrm{m}^{-2}$ was the lowest significance. The adhesive bond strength increase depends on good wettability of reinforcing phase in adhesive which is evident from Fig. $5 \mathrm{~B}$ and $\mathrm{C}$.

SEM analyses Fig. 5 B, C and 6 A, B, C showed that epoxy resin " $\mathrm{R}$ " was on glass fibre surface and between the fibres. This penetration of adhesive in fabric means good wettability between each fibre which cross themselves in angle $90^{\circ}$. The same conclusion had Santana et al. [24]. Especially, fibres oriented at $90^{\circ}$ relative to the direction of the strain may function as a barrier during the matrix phase deformation when hybrid joints are considered [24]-[26]. From Fig. 6 A and B is evident special failure type combinate adhesion and cohesion failure of bond.
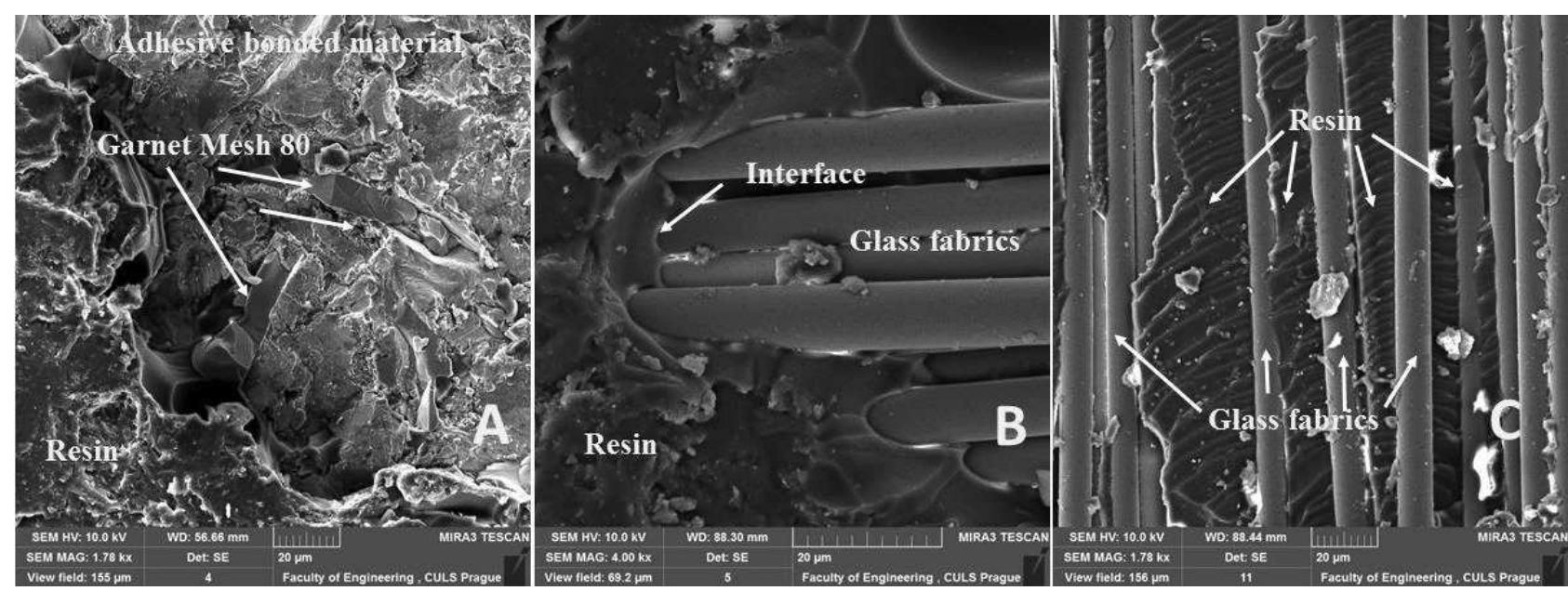

Fig. 5 SEM images of fracture surface (detector $S E$ ): A: fracture surface of adhesive bond " $R$ ” with no reinforcing fabric (MAG $1.78 \mathrm{kx})$, B: fracture surface of adhesive bond with reinforcing fabric $160 \mathrm{~g} . \mathrm{m}^{-2}$ " $R R G F 160$ ” (MAG 4:00 kx), $C$ : fracture surface of adhesive bond with reinforcing fabric $160 \mathrm{~g} . \mathrm{m}^{-2}$ "RRGF160" (MAG $1.78 \mathrm{kx}$ ). 

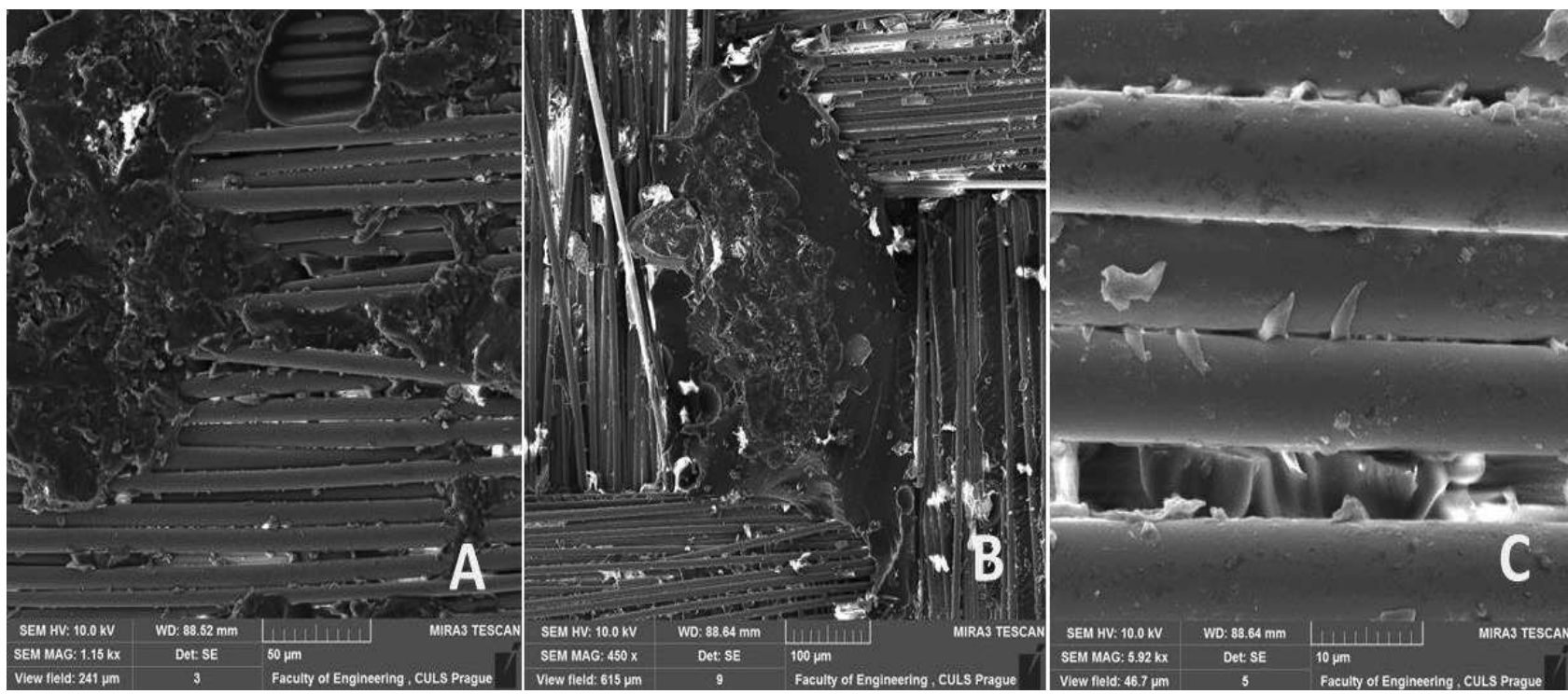

Fig. 6 SEM images of fracture surface (detector $S E$ ): A: special type of adhesive bond failure with reinforcing fabric 160 g.m "RRGF160" (MAG1.15 kx), B: special type of adhesive bond failure with reinforcing fabric $110 \mathrm{~g} . \mathrm{m}^{-2}$

"RRGF110" (MAG 450 x), C: detailed view on interaction between fibre of fabric $110 \mathrm{~g} \cdot \mathrm{m}^{-2}$ and the adhesive (MAG $5.92 k x$

\section{Conclusions}

This research describes influence of adherent modification and reinforcing of adhesive for a purpose to increase the strength of adhesive bond on hybrid base. The following point summarize all results of the research:

- Statistical testing proved significant difference on influence of the adhesive bond strength by preformed adherent angle on significance level 0.05 i.e. the preformed adherent angle significantly influence the adhesive bond strength.

- Statistical testing proved significant difference on influence of the adhesive bond strength by glass fabric on significance level 0.05 i.e. the glass fabric significantly influence the adhesive bond strength.

- The adhesive bond strength with no modification is $8.82 \pm 0.54 \mathrm{MPa}$.

- The highest strength $13.1 \pm 0.25 \mathrm{MPa}$ was achieved with modification of adherent by angle $5^{\circ}$ and fabric $80 \mathrm{~g} \cdot \mathrm{m}^{-2}$. The strength increase up to $48.50 \%$ against the adhesive bond with no modification.

- The lowest strength $6.29 \pm 1.51 \mathrm{MPa}$ was achieved with modification of adherent by angle $20^{\circ}$ with no adhesive reinforcing. The strength decrease up to $28.69 \%$ against the adhesive bond with no modification.

- The reinforcing fabric and preformed angle of adherent had a positive impact on mechanical properties and changed the type failure of adhesive bond.

\section{Acknowledgement}

This paper has been made with the assistance of the grant IGA TF CZU (Research on composite layer interactions at hybrid adhesive bonds, Czech University of Life Sciences Prague no. 2019:31140/1312/313108).

\section{References}

[1] BANEA, M. D., ROSIOARA, M., CARBAS, R. J. C. and DA SILVA, L. F. M. (2018). Multimaterial adhesive joints for automotive industry. In: Compos. Part B Eng., Vol. 151, pp. 71-77.

[2] KOLÁř, V., TICHÝ, M., MÜLlER, M., VALÁŠEK, P. and RUDAWSKA, A. (2019). Research on influence of cyclic degradation process on changes of structural adhesive bonds mechanical properties. In: Agron. Res., Vol. 17, No. S1, pp. 1062-1070.

[3] RUDAWSKA, A., MITURSKA, I., SZABELSKI, J., SKOCZYLAS, A., DROŹDZIEL, P., BOCIĄGA, E., MADLEŇÁK, R., and KASPEREK, D. (2017). Experimental research and statistic analysis of polymer composite adhesive joints strength. In: J. Phys. Conf. Ser., Vol. 842, No. 1, p. 012074.

[4] KATNAM, K. B., COMER, A. J., STANLEY, W. F., BUGGY, M., ELlingBOE, A. R. and YOUNG, T. M. (2011). Characterising pre-preg and non-crimp-fabric composite single lap bonded joints. In: Int. J. Adhes. Adhes., Vol. 31, No. 7, pp. 679-686.

[5] KAHRAMAN, R., SUNAR, M. and YILBAS, B. (2008). Influence of adhesive thickness and filler content on the mechanical performance of aluminum single-lap joints bonded with aluminum 
powder filled epoxy adhesive. In: J. Mater. Process. Technol., Vol. 205, No. 1-3, pp. 183189.

[6] COURT, R. S., SUTClifFE, M. P. F. and TAVAKOLI, S. M. (2001). Ageing of adhesively bonded joints - fracture and failure analysis using video imaging techniques. In: Int. J. Adhes. Adhes., Vol. 21, No. 6, pp. 455-463.

[7] MÜllER, M., VALÁŠEK, P., KOLÁŘ, V., ŠLEGER, V., GÜRDIL, G. A. K., HROMASOVÁ, M., HLOCH, S., MORAVEC, J. and PEXA, M. (2018). Material Utilization of Cotton Post-Harvest Line Residues in Polymeric Composites. In: Polymers (Basel)., Vol. 11, No. 7, pp. 1106.

[8] RUDAWSKA, A., HANIECKA, I., JASZEK, M. and STEFANIUK, D. (2018) The influence of adhesive compounds biochemical modification on the mechanical properties of adhesive joints. In: Polymers (Basel)., Vol. 10, No. 4, pp. 344.

[9] MÜLLER, M., VALÁŠEK, P., and RUDAWSKA, A. (2017). Mechanical properties of adhesive bonds reinforced with biological fabric. In: J. Adhes. Sci. Technol., Vol. 31, No. 17, pp. 1859-1871.

[10] KOLAR, V. and MULLER, M. (2018). Research on Influence of Polyurethane Adhesive Modified by Polyurethane Filler Based on Recyclate. In: Manuf. Technol., Vol. 18, No. 3, pp. 418-423.

[11] MÜLLER, M., (2015). Research on constructional shape of bond at connecting galvanized sheet of metal. In: Manuf. Technol., Vol. 15, No. 3, pp. 392-396.

[12] FESSEL, G., BROUGHTON, J. G., FELLOWS, N. A., DURODOLA, J. F., and HUTCHINSON, A. R. (2007). Evaluation of different lap-shear joint geometries for automotive applications. In: Int. J. Adhes. Adhes., Vol. 27, No. 7, pp. 574-583.

[13] BAHRAMI, B., AYATOLLAHI, M. R., BEIGREZAEE, M. J. and DA SILVA, L. F. M. (2019). Strength improvement in single lap adhesive joints by notching the adherents. In: Int. J. Adhes. Adhes., Vol. 95, pp. 102401.

[14] HE, X. (2011). A review of finite element analysis of adhesively bonded joints. In: Int. J. Adhes. Adhes., Vol. 31, No. 4, pp. 248-264.

[15] YOU, M., LI, Z., LING ZHENG, X., YU, S., YAN LI, G. and XIN SUN, D. (2009). A numerical and experimental study of preformed angle in the lap zone on adhesively bonded steel single lap joint. In: Int. J. Adhes. Adhes., Vol. 29, No. 3, pp. 280285.

[16] ÁVILA, A. F., BUENO, P. (2003). Stress analysis on a wavy-lap bonded joint for composites. In: Int. J. Adhes. Adhes., Vol. 24, pp. 407-414.

[17] ÁvilA, A. F., BUENO, P. O. (2004). An experimental and numerical study on adhesive joints for composites. In: Compos. Struct., Vol. 64, pp. 531-537.

[18] CAMPILHO, R. D. S. G., DOMINGUES, J. J. M. S. (2009): Numerical prediction on the tensile residual strength of repaired CFRP under different geometric changes. In: Int. J. Adhes. Adhes., Vol. 29, pp. 195-205.

[19] MÜLLER, M., HERÁK, D. (2010). Dimensioning of the bonded lap joint. In: Res. Agri. Eng., Vol. 56, No. 2, pp. 59-68.

[20] GRANT, L.D.R., ADAMS, R.D., DA SILVA, L.F.M. (2009). Experimental and numerical analysis of single-lap joints for the automotive industry. In: Int. J. Adhes. Adhes. Vol. 29.

[21] ZAVRTÁLEK, J., MÜLLER, M. (2016). Research on mechanical properties of adhesive bonds reinforced with fabric with glass fibres. In: Manufacturing Technology, Vol. 16, No. 1, pp. 299-304.

[22] ZAVRTÁLEK, J., MÜLLER, M. and ŠLEGER, V. (2016). Low-cyclic fatigue test of adhesive bond reinforced with glass fibre fabric. In: Agro. Res., Vol. 4, pp. 1138-1146.

[23] MÜLLER, M. (2017). Effect of surface treatment of adhesive bonded sheet of aluminium alloy EN AW 2024 T3 on adhesive bond strength created by means of structural two-component adhesive. In: Manuf. Tech., Vol. 17, No. 5, pp. 791-796.

[24] SANTANA, P. R. T., PANZERA, T. H., FREIRE, R. T. S., and CHRISTOFORO, A. L. (2017). Apparent shear strength of hybrid glass fibre reinforced composite joints. In: Polym. Test., Vol. 64, pp. 307-312.

[25] CAO, Y., CAMERON, J. (2006) Impact properties of silica particle modified glass fiber reinforced epoxy composite. In: J. Reinf. Plastics Compos., Vol. 25, pp. 761-769.

[26] CAO, Y., CAMERON, J. (2006) Flexural and shear properties of silica particle modified glass fiber reinforced epoxy composite. In: J. Reinf. Plastics Compos., Vol. 25, pp. 347-359. 